\title{
INFLUÊNCIA DA ETAPA DE DISSOLUÇÃO DO ENCAPSULANTE POR SOLVENTE ORGÂNICO NA LIXIVIAÇÃO DE PRATA DE PAINÉIS FOTOVOLTAICOS *
}

Pedro Forastieri de Almeida Prado ${ }^{1}$
Jorge Alberto Soares Tenório
Denise Crocce Romano Espinosa

\section{Resumo}

A fim de recuperar-se todos os materiais presentes em painéis fotovoltaicos, 0 emprego de solventes orgânicos para promover a dissolução da fração polimérica e liberação dos componentes é uma alternativa ao tratamento térmico tradicional. Com o objetivo de verificar-se o impacto dessa etapa na recuperação de prata, o metal de maior valor presente nos painéis de silício cristalino, comparou-se taxas de recuperação de prata para rotas distintas de separação de materiais e cominuição: uma rota por dissolução do encapsulante através de solventes e uma rota por tratamento térmico e destruição do encapsulante. Utilizando-se o isopropanol como solvente, ainda foi analisada a contribuição da cominuição para a liberação da prata. Os ensaios de lixiviação foram realizados com soluções de $5 \mathrm{M} \mathrm{HNO}_{3}$, analisando-se as concentrações de prata por ICP-MS. O processo de calcinação foi realizado em forno a $480^{\circ} \mathrm{C}$, a dissolução do encapsulante realizada com isopropanol e a cominuição realizada em moinho de facas. Foi concluído que a separação com isopropanol não afetou a quantidade de prata lixiviada na etapa de recuperação de metais. Além disso identificou-se que a cominuição não seria necessária sob as condições de lixiviação utilizadas, já que poderia potencialmente contribuir para perda de prata no processo.

Palavras-chave: Painel solar; Reciclagem; Prata; Isopropanol

\section{INFLUENCE OF ENCAPSULANT DISSOLUTION BY ORGANIC SOLVENT ON SILVER LEACHING FROM PHOTOVOLTAIC PANELS}

\section{Abstract}

In order to recover all materials present in photovoltaic (PV) modules, the use of organic solvents to dissolve the encapsulant and liberate the materials can be an alternative to the traditional thermal treatment employed. To measure the impact of this step on the later process of silver leaching, the most valuable metal present in crystalline PV modules, different routes employing these material separation steps and comminution were evaluated according to silver recovery: a route comprising thermal treatment and destruction of the encapsulant followed by comminution and a second route comprising dissolution of the encapsulant followed by comminution. The impact of comminution was also evaluated for the organic solvent separation route with a nonmilled sample. The leaching experiments were performed with $5 \mathrm{M} \mathrm{HNO}$ solutions, analyzing the silver concentrations by ICP-OES. The calcination was done at $480^{\circ} \mathrm{C}$, the encapsulant dissolution performed with isopropanol and the comminution performed in a knive mill. It was concluded that the separation process with isopropanol did not interefere with the quantity of silver leached. Moreover comminution would not be necessary under the leaching conditions used, since it could potentially contribute to silver losses throughout the process.

Keywords: Solar panel; Reciclagem; Silver; Isopropanol 
1 Aluno de Mestrado, Engenheiro Químico, Laboratório de Reciclagem, Tratamento de Resíduos e Metalurgia Extrativa (LAREX), Departamento de Engenharia Química, Universidade de São Paulo, São Paulo, São Paulo, Brasil.

2 Professor Titular, Engenheiro Metalurgista, Laboratório de Reciclagem, Tratamento de Resíduos e Metalurgia Extrativa (LAREX), Departamento de Engenharia Química, Universidade de São Paulo, São Paulo, São Paulo, Brasil.

3 Professora Associada, Engenheiro Metalurgista, Laboratório de Reciclagem, Tratamento de Resíduos e Metalurgia Extrativa (LAREX), Departamento de Engenharia Química, Universidade de São Paulo, São Paulo, São Paulo, Brasil. 


\section{INTRODUÇÃO}

\section{Painéis fotovoltaicos}

A tecnologia fotovoltaica tem sido extensamente empregada nas últimas décadas a fim de substituir fontes de energia não renováveis como combustíveis fósseis, os quais geram gases de efeito estufa e assim contribuem para o aquecimento global [1]. Essa tecnologia têm apresentado taxa de crescimento de $45 \%$ na matriz energética mundial, atingindo participação de aproximadamente 200GW em 1800GW [2].

Dentre os painéis fotovoltaicos fabricados ao redor do mundo, os de silício multicristalino/policristalino são os mais empregados, compreendendo aproximadamente $70 \%$ do market share de painéis (Figura 1). Diferem-se do segundo tipo mais utilizado, os de silício monocristalino, apenas no tipo de semicondutor empregado [2].

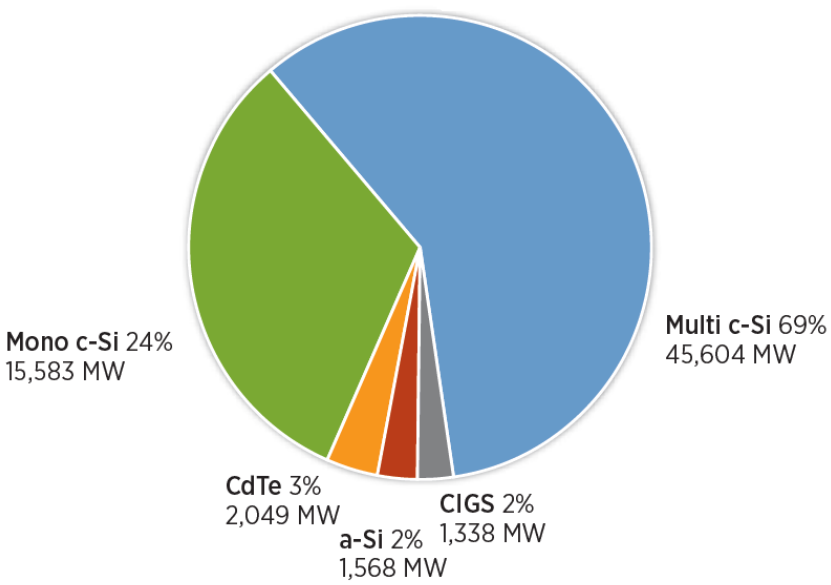

Figura 1. Mercado mundial de painéis fotovoltaicos por tecnologia em 2015 [2].

2. Fim de vida e resíduos fotovoltaicos

Juntamente com a expansão do mercado de painéis fotovoltaicos, crescem as perspectivas de resíduos gerados por essa tecnologia. Por um longo período os painéis não foram associados à um problema de resíduos sólidos devido ao fenômeno de lag time, ocasionado pelo longo período entre a produção e o descarte desse resíduo sólido [3]. No entanto essa perspectiva mudou, com previsões preocupantes. Até 2050, 78 milhões de toneladas de resíduos fotovoltaicos ao redor do mundo serão gerados (Figura 2) [4]. 

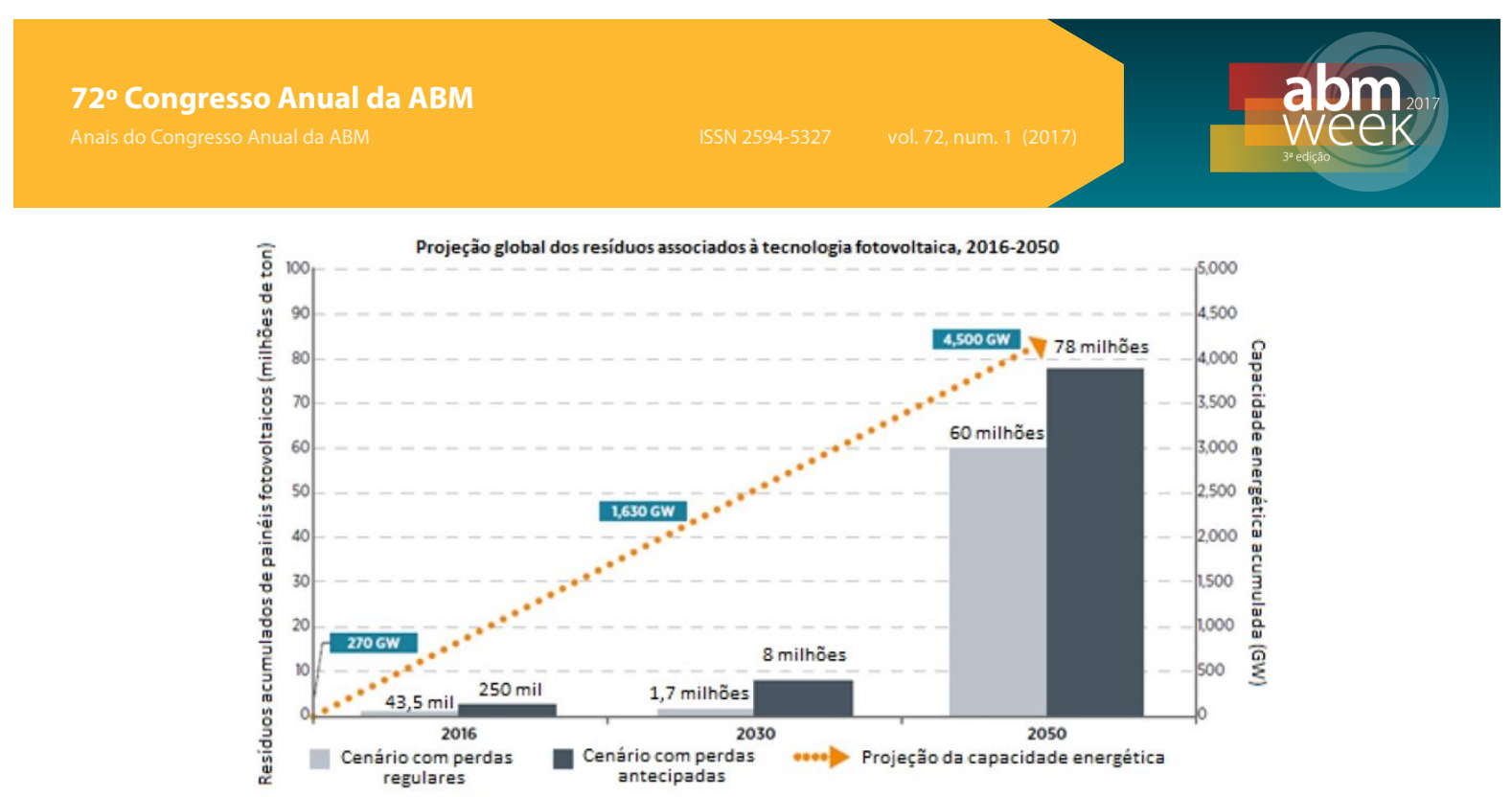

Capacidade energética acumulada (GW)

Figura 2. Projeção da geração de resíduos provenientes de painéis fotovoltaicos de 2016 a 2050 [5].

Considera-se o fim de vida de um painel quando o mesmo apresenta danos físicos ou atinge-se $80 \%$ de sua eficiência nominal [6]. A queda de eficiência observada ao longo dos anos se dá principalmente pela degradação do material encapsulante, o qual agrupa todos os materiais no módulo, pela radiação ultravioleta incidente $[7,8,9,10]$.

3. Materiais presentes em painéis fotovoltaicos de silício policristalino

Os painéis fotovoltaicos apresentam uma grande variedade de materiais na sua composição. O principal material presente nesses painéis é a celular solar, composta do material semicondutor de silício policristalino, sendo depositada sob a sua superfície trilhas de prata (Figura 3-a e 3-b). As trilhas de prata auxiliam na coleta dos elétrons gerados pelo material semicondutor, conduzindo-os aos ribbons, contatos metálicos que ligam as células ao conversor de energia no exterior do painel [11]. A prata é um metal não só de preocupação ambiental, por ser bioacumulativo e tóxico para os seres vivos [12], como também tem alto valor de mercado e estratégico para eletroeletrônicos $[13,14]$, sendo de interesse comercial sua recuperação.
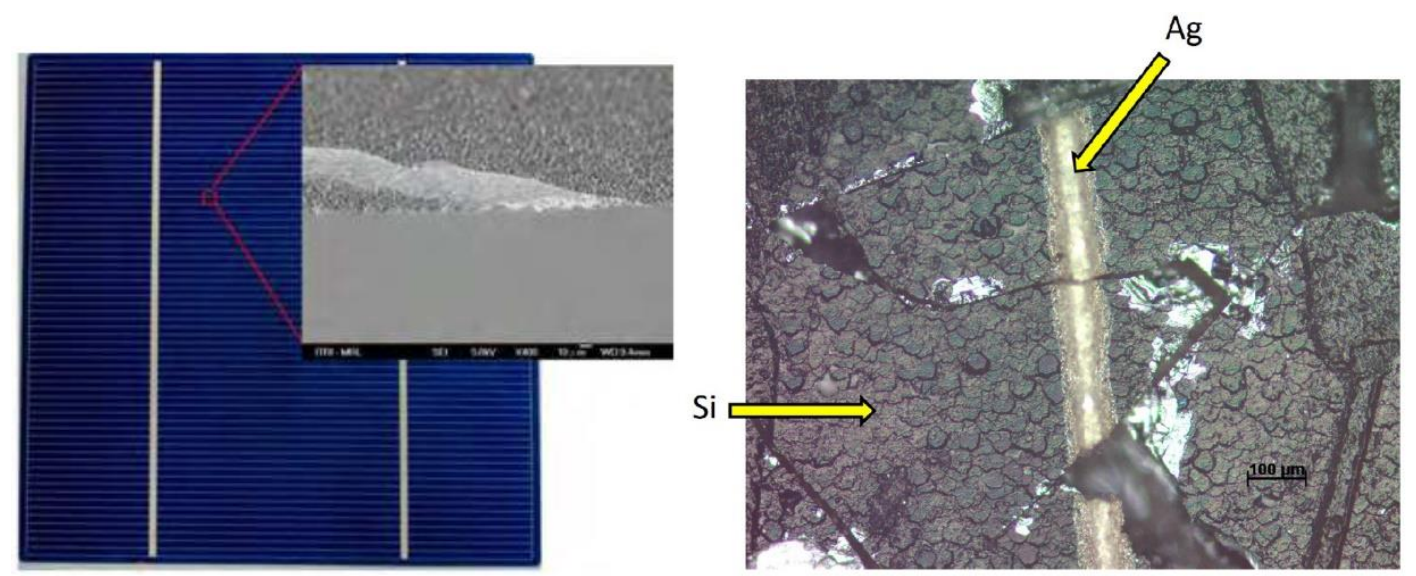

Figura 3. (a) MEV de uma superfície de célula solar, denotando-se a região onde a pasta de prata é depositada [11]; (b) Microscopia óptica de amostra de placa solar de silício cristalino, com magnificação de 100x [15].

Apesar disso, outros materiais são empregados em painéis fotovoltaicos (Figura 4-a), auxiliando à proteção do semicondutor e à sua estabilização mecânica na estrutura do módulo. A superfície dos painéis é normalmente composta de vidro e o backsheet, 
normalmente de Tedlar/PET/Tedlar (TPT) [4]. Para fixar-se a célula solar entre essas camadas e prover proteção mecânica, um material conhecido como encapsulante é utilizado (Figura 4-b).

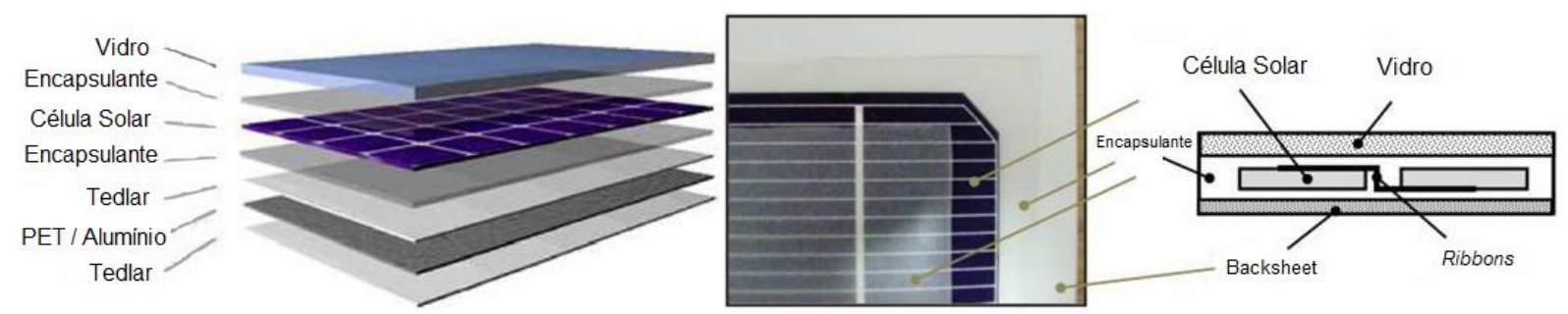

Figura 4. (a) Estratificação dos materiais em um painel fotovoltaico de silício policristalino. Adaptado de [16]; (b) Encapsulante de EVA e materiais adjacente em um módulo fotovoltaico. Adaptado de [17].

Os materiais encapsulantes mais comuns englobam os poliuretanos, etileno vinil acetato (EVA), poliolefina termoplástica, polidimetilsiloxano (PDMS, silicone), polivinil butiral (PVB) $[18,19]$.

A substituição do etileno vinil acetato (EVA), o material encapsulante mais comum (90\% do market share), por compostos de poliolefina e silicones (PDMS, em particular) assume uma tendência de crescimento na qual o silicone apresentará $5 \%$ do mercado fotovoltaico (Figura 5). Esse material pode extender a vida útil dos painéis em até 50 anos, oferecendo resistência à umidade e radiação ultravioleta $[18,20]$.

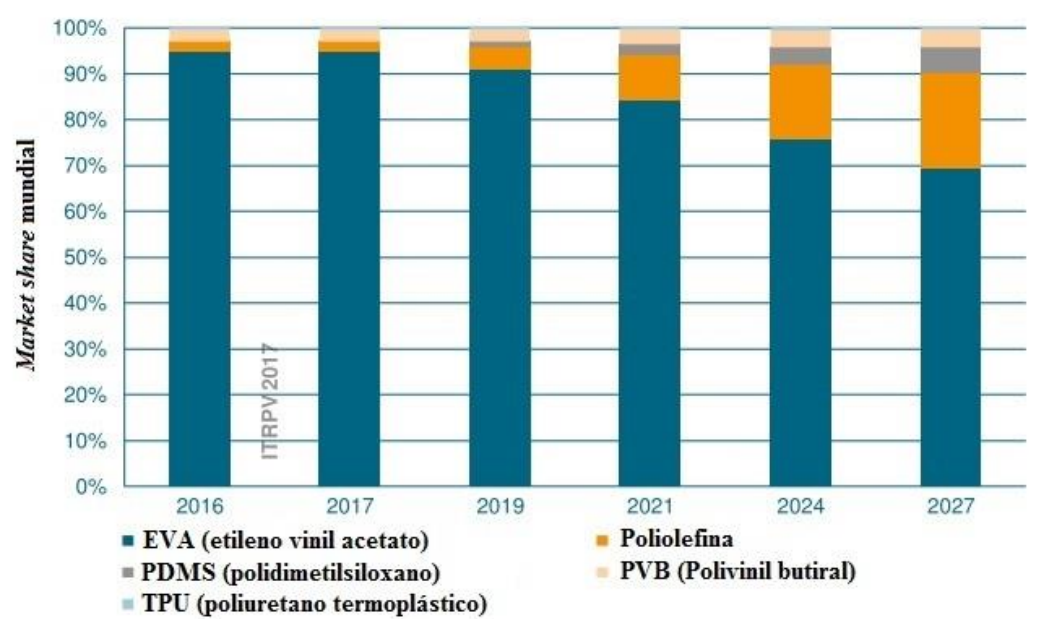

Figura 5. Projeções de market share para diferentes encapsulantes em aplicações fotovoltaicas [21].

4. Separação dos componentes e recuperação de metais

Para a etapa de separação de materiais, normalmente emprega-se um tratamento térmico [15,22]. A calcinação visa decompor o encapsulante, normalmente de EVA, destruindo-o e liberando os metais, vidro e semicondutor do painel. Pelo custo benefício e agilidade desse processo, tem sido o mais reportado na literatura [23].

Essa etapa, no entanto, tem sido alvo recentemente de pesquisas quanto ao seu impacto ambiental. A emissão de poluentes para a atmosfera se dá através da formação de compostos orgânicos tóxicos, como dioxinas e furanos, durante a 
combustão do encapsulante [8] e a emissão de metais, como prata e chumbo, advindos da pasta de prata empregada nas trilhas condutoras [23,24].

Como alternativa à esse processo, o método de dissolução do encapsulante, e consequente liberação de componentes, através do uso de solventes orgânicos foi primeiramente proposto por [9] e estudado por [25] para encapsulante de EVA e por [26] para um encapsulante de PDMS, potencialmente eliminando a emissão de compostos tóxicos para a atmosfera. No entanto o impacto do tratamento por uso de solventes quanto à possibilidade de arraste de metais a partir da fase sólida para a fase líquida, diminuindo a eficiência de recuperação desses metais em etapas posteriores da reciclagem, ainda não foi verificado.

Na literatura, a lixiviação de prata a partir de painéis fotovoltaicos envolve o uso de ácido nítrico, por ser um dos agentes mais eficiente $[15,17,22]$ para a prata em painéis fotovoltaicos. Esse agente será utilizado para avaliar os impactos causados pelo método de separação com solvente orgânico na lixiviação de prata. Estudou-se, portanto, o impacto do uso de isopropanol, utilizado para dissolver o PDMS presente em um painel, na posterior etapa de lixiviação de prata.

\section{MATERIAIS E MÉTODOS}

\subsection{Caracterização da prata presente nos painéis fotovoltaicos}

A concentração de prata no painel de silício policristalino utilizado (Figura 6) foi avaliada de acordo com uma digestão em água régia (3 partes de ácido clorídrico para 1 parte de ácido nítrico) em um Becker, de acordo com procedimento de [15] e uma segunda digestão, em ácido nítrico $64 \%$, a fim de eliminar-se qualquer possibilidade da formação de cloreto de prata. A razão sólido-líquido utilizada nas duas caracterizações foi de $0,1 \mathrm{~g} \cdot \mathrm{L}^{-1}$ sob agitação em 2 horas a $60^{\circ} \mathrm{C}$.

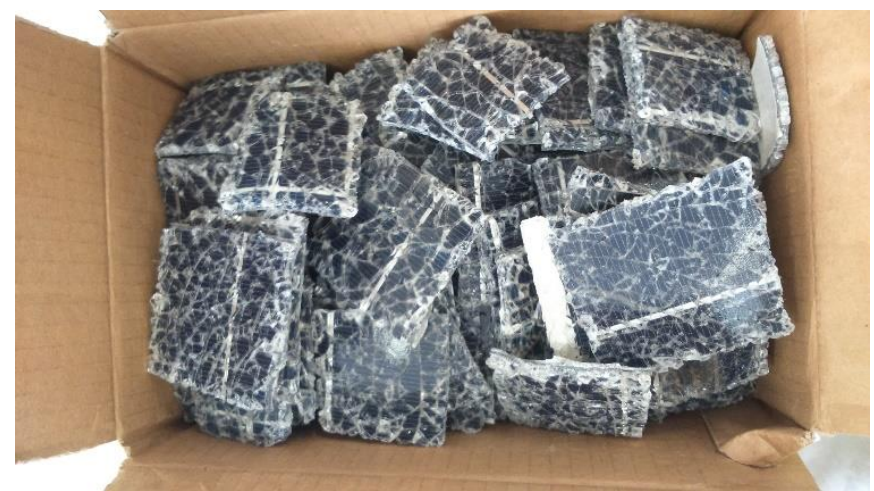

Figura 6. Amostras de painel de silício policristalino.

\subsection{Separação dos componentes presentes nos painéis}

A separação de materiais para obter-se somente o semicondutor e consequentemente a superfície na qual a prata estava presente, ocorreu por dois métodos. 
O primeiro método envolveu a metodologia tradicional de tratamento térmico, para painéis em geral, aplicando-se uma temperatura de $480^{\circ} \mathrm{C} \mathrm{a} 15^{\circ} \mathrm{C} / \mathrm{min}$, sob atmosfera de ar em um forno da marca Jung (Figura 7-a) [22].

O segundo método utilizado foi a dissolução do encapsulante através de imersão de amostra do painel com área de 5 por $5 \mathrm{~cm}^{2}$ por 2 dias em isopropanol PA (Figura 7b), utilizando-se relação sólido-líquido de $0,2 \mathrm{~g} \cdot \mathrm{mL}^{-1}$ a temperatura ambiente [26]. Após 2 dias, a mistura foi filtrada e seca em estufa a $60^{\circ} \mathrm{C}$ por 1 dia, recuperando-se o semicondutor.



Figura 7. (a) Forno Jung, onde foi realizado o tratamento térmico da amostra de painel fotovoltaico. (b) Becker com amostra de painel imersa em isopropanol.

\subsection{Cominuição e classificação granulométrica}

A cominuição foi utilizada em duas das três rotas estudadas para recuperar-se a prata. Foi realizada em um moinho de facas da marca Marconi (Figura 8), em 2 etapas de moagem com grelhas de tamanhos $3 \mathrm{~mm}$ e $1 \mathrm{~mm}$.

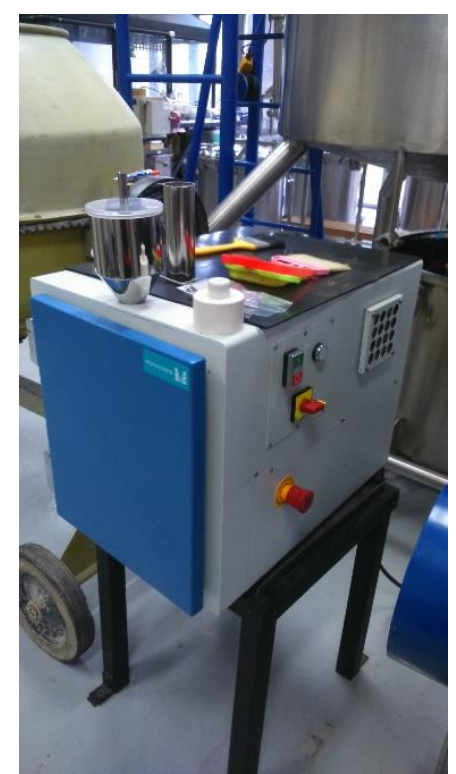

Figura 8. Moinho de facas Marconi, onde foi realizada a moagem de amostras.

[27] notou que $81 \%$ da prata estava concentrada em partículas menores que $0,5 \mathrm{~mm}$ nos painéis. A fim de verificar-se qual fração granulométrica seria usada nas rotas de lixiviação, realizou-se a classificação granulométrica por meio de um agitador e peneiras com abertura de tamanho $0,01 \mathrm{~mm}, 0,038 \mathrm{~mm}, 0,075 \mathrm{~mm}, 0,125 \mathrm{~mm}$, $0,250 \mathrm{~mm}, 0,500 \mathrm{~mm}$ e $1,000 \mathrm{~mm}$. 


\subsection{Lixiviação de prata}

A lixiviação de prata com ácido nítrico foi realizada utilizando-se amostras de painel de diferentes processamentos. A primeira rota de lixiviação envolveu o painel de silício cristalino separado por tratamento térmico tradicional, seguido de cominuição em moinho de facas. A segunda amostra foi separada por dissolução do encapsulante por isopropanol, de acordo com [26]. A terceira amostra foi também separada com isopropanol, no entanto passou-se a amostra posteriormente por cominuição em um moinho de facas.

As condições de lixiviação utilizadas envolveram o uso de soluções de ácido nítrico $5 \mathrm{M}$, relação-sólido líquido $0,1 \mathrm{~g} \cdot \mathrm{mL}^{-1}\left(20 \mathrm{~g}\right.$ de painel para $200 \mathrm{~mL}$ de solução), $60^{\circ} \mathrm{C}$ e 2 horas de experimento com agitação magnética. Foi utilizado o reator automatizado Atlas Potassium, controlando-se a temperatura através do medidor de temperatura conectado à base do reator $\mathrm{e} o$ banho termostático conectado à camisa do reator (Figura 9). A concentração de prata nas soluções foi analisada por espectrometria de emissão óptica por plasma acoplado indutivamente (ICP-OES).

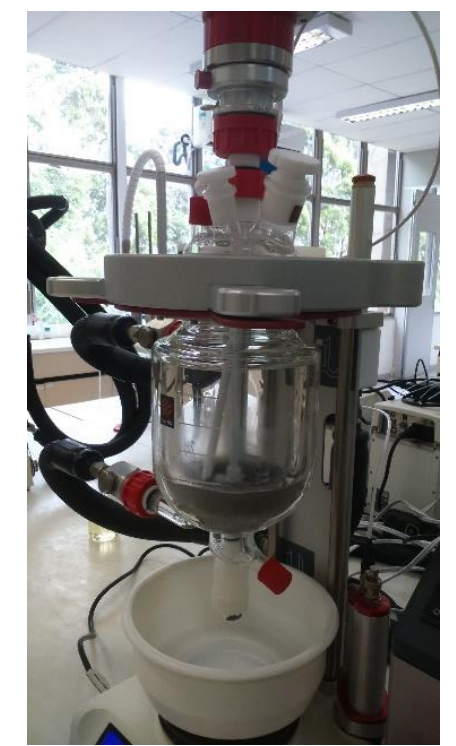

Figura 9. Reator encamisado Atlas Potassium utilizado para os experimentos de lixiviação de prata com ácido nítrico.

\section{RESULTADOS E DISCUSSÃO}

\subsection{Caracterização dos painéis fotovoltaicos}

A caracterização com água régia e ácido nítrico resultou em concentração de prata de aproximadamente $0,0630 \%$ em massa de painel. Esse valor está de acordo com o valor apontado na literatura [15], que seria de $0,0635 \%$ em massa ou ainda, $635 \mathrm{~g} / \mathrm{t}$, ao caracterizar-se o painel com água régia.

\subsection{Separação dos componentes presentes nos painéis}


A separação por tratamento térmico destruiu completamente o encapsulante juntamente com o backsheet. Os contatos metálicos (ribbons) apresentaram fortes indícios visuais de degradação (Figura 10-a). A separação dos painéis por dissolução do encapsulante através de imersão em isopropanol durou 2 dias, e pôde-se obter os compostos oriundos da dissolução após secagem dos mesmos em estufa (Figura 10b).
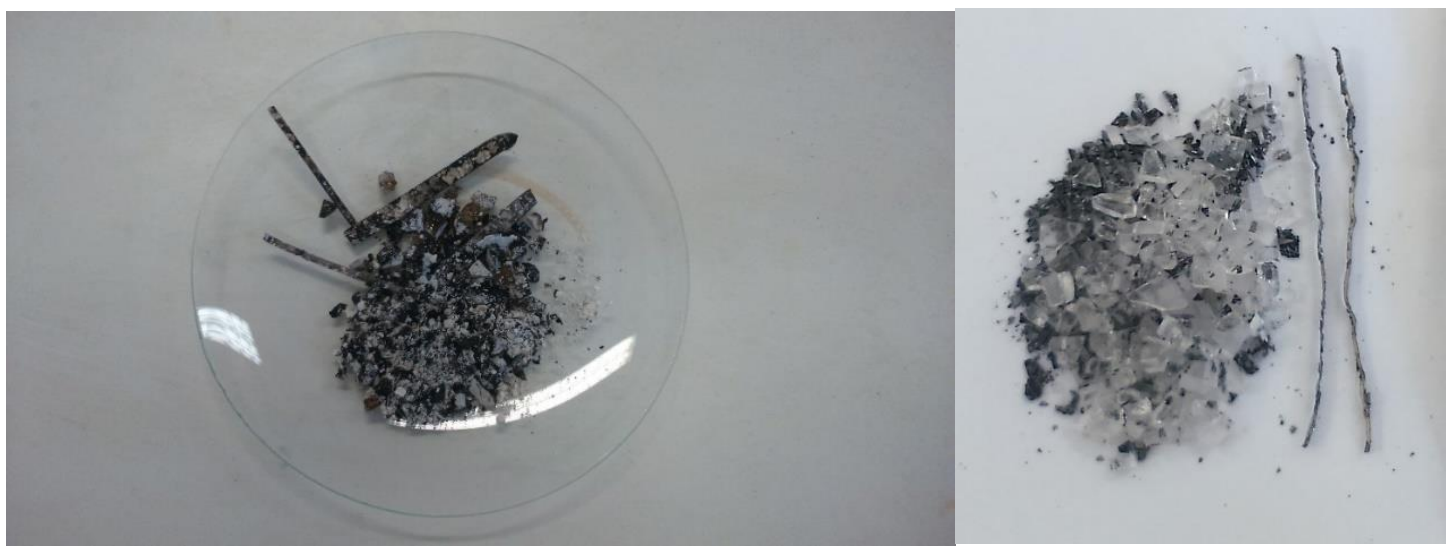

Figura 10. Materiais liberados através (a) Sólido obtido da calcinação do painel fotovoltaico a $480^{\circ} \mathrm{C}$ (b) dissolução do encapsulante com isopropanol.

\subsection{Cominuição e classificação granulométrica}

A cominuição da amostra oriunda do tratamento térmico foi realizada em 2 estágios. Após a moagem em grelhas de $3 \mathrm{~mm}$ e $1 \mathrm{~mm}$, o pó resultante foi classificado no classificador granulométrico, rendendo o perfil de distribuição granulométrica descrito na Figura 11.

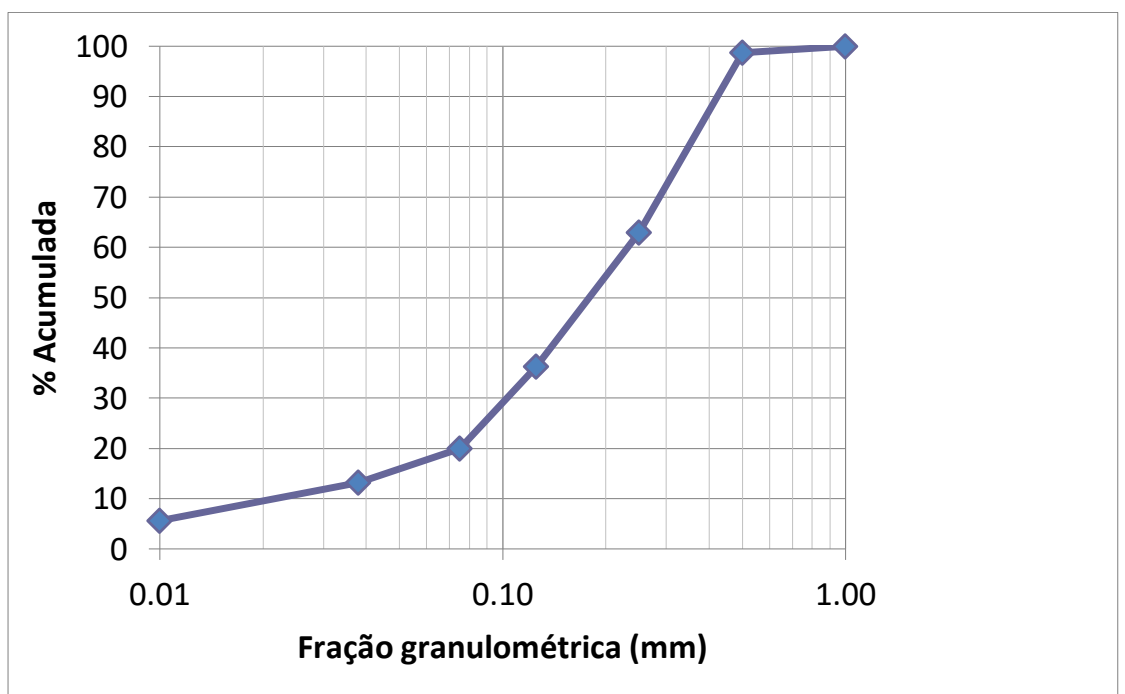

Figura 11. Perfil granulométrico acumulado de amostra separada por tratamento térmico e cominuída em moinho de facas.

Pode-se observar que aproximadamente $98,8 \%$ (em massa) compreendeu granulometria menor que $0,5 \mathrm{~mm}$ e, portanto, foi utilizada a amostra por completo para a lixiviação. 
A cominuição da amostra oriunda da dissolução do encapsulante por isopropanol também foi realizada em 2 estágios com grelhas de $3 \mathrm{~mm}$ e $1 \mathrm{~mm}$, classificando-se a granulometria do produto final (Figura 12).

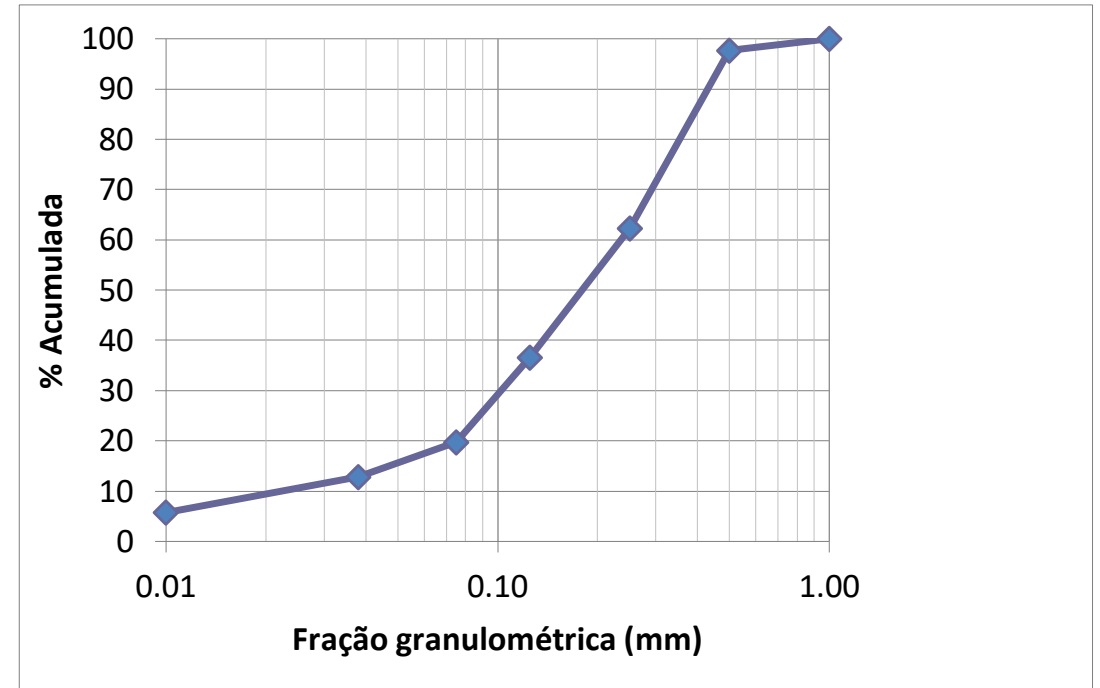

Figura 12. Perfil granulométrico acumulado de amostra separada por dissolução do encapsulante por isopropanol e cominuída em moinho de facas.

Comparativamente à amostra separada por tratamento térmico, a amostra separada por isopropanol apresentou distribuição granulométrica muito similar. Por volta de $98,8 \%$ da amostra (em massa) compreendeu granulometria menor que $0,5 \mathrm{~mm}$, logo toda a amostra foi utilizada para a rota de lixiviação.

\subsection{Lixiviação de prata}

A fim de avaliar-se o impacto de cada rota de separação na lixiviação de prata, o produto da separação foi submetido a lixiviação no reator automatizado Atlas Potassium e as concentrações de prata foram obtidas pelo ICP-OES, dispostas na Tabela 1 abaixo.

Tabela 1. Concentração de prata no lixiviado de cada tratamento utilizado

\begin{tabular}{cc}
\hline Tratamento & $\begin{array}{c}\% \mathbf{A g} \\
\text { Lixiviado }\end{array}$ \\
\hline Isopropanol & $95 \%$ \\
\hline Isopropanol+Cominuição & $86 \%$ \\
\hline Calcinação+Cominuição & $84 \%$ \\
\hline
\end{tabular}

A lixiviação de prata com ácido nítrico $5 \mathrm{M}$ revelou ter extraído grande parte da prata do resíduo fotovoltaico para todos os tratamentos. Os resultados revelaram estarem próximos aos da lixiviação realizada por [15], que conseguiu recuperar $94 \%$ da prata ao utilizar um ácido mais concentrado, ácido nítrico PA (64\%) e realizou precipitação com cloreto de sódio.

Observou-se que não houve diferenças com relação às amostras tratadas por isopropanol e por calcinação, submetidas à cominuição. A diferença na porcentagem de prata lixiviada é muito pequena, concluindo-se que não houve impacto na lixiviação de prata de um tratamento para o outro. O uso de isopropanol para a separação dos materiais seria satisfatório do ponto de vista da recuperação da prata. 
Quanto às amostras tratadas com isopropanol, ao realizar-se cominuição notou-se que a quantidade de prata lixiviada diminuiu. Isso pode ser explicado pelas perdas na moagem, já que maior parte da prata está concentrada em tamanhos de partícula menores que $0,5 \mathrm{~mm}$ e portanto, mais suscetíveis à perdas inerentes do processo de cominuição, seja por extravio no interior do moinho, seja por emissões à atmosfera.

\section{CONCLUSÃo}

Os resultados indicaram que a concentração de prata no painel de silício policristalino utilizado estava de acordo com o valor obtido na literatura, correspondendo a $0,0630 \%$ de prata em massa de painel. Concluiu-se que não houve impacto na lixiviação de prata, decorrente do método de separação empregado, obtendo-se porcentagens muito similares. Concluiu-se também que a cominuição gerou perdas, as quais diminuíram a eficiência de lixiviação de prata. O tratamento com isopropanol, sem cominuição, revelou ser o melhor processamento para obter-se a solução de maior concentração de prata.

\section{Agradecimentos}

Agradecimentos ao suporte da Coordenação de Aperfeiçoamento de Pessoal de Nível Superior (CAPES) pelo suporte financeiro através da bolsa de mestrado e da Fundação de Amparo à Pesquisa do Estado de São Paulo (FAPESP) pelo suporte financeiro através do Projeto de Pesquisa 2012/51871-9. Agradecimentos ao Prof. Roberto Zilles do Instituto de Energia e Ambiente (IEE-USP) da Universidade de São Paulo pela doação dos painéis fotovoltaicos.

\section{REFERÊNCIAS}

1 Solar power Technologies for sustainable electricity generation - a review. Renewable and Sustainable Energy Reviews. 2016;

2 Philipp B, Tian T. 2015 Renewable Energy Data Book. 2016 [acesso em 15 maio 2017]. Disponível em: www.nrel.gov/docs/fy17osti/66591.pdf.

3 Zhong ZW, Song B, Loh PE. LCAs of a polycrystalline photovoltaic module and a wind turbine. Renew. Energy. 2011;36(8):2227-2237.

4 International Renewable Energy Agency (IRENA). End-of-life management: Solar Photovoltaic Panels. 2016 [acesso em 15 de maio 2017]. Disponível em: http://www.irena.org/DocumentDownloads/Publications/IRENA_IEAPVPS_End-ofLife_Solar_PV_Panels_2016.pdf

5 Hagelüken C, Meskers CEM. Complex Life Cycles of Precious and Special Metals. In: Graedel VV. Linkages of Sustainability. Cambridge: MIT Press; 2009, p. 163-197.

6 Kazmerski LL. Solar photovoltaics R \& D at the tipping point: A 2005 technology overview. 2006; 150:105-135.

7 Czanderna AW, Pern FJ. Encapsulation of PV modules using ethylene vinyl acetate copolymer as a pottant: A critical review. Sol. Energy Mater. Sol. Cells. 1996;43(2):101181.

8 Pern FJ, Czanderna AW. Characterization of ethylene vinyl acetate (EVA) encapsulant: Effects of thermal processing and weathering degradation on its discoloration. Sol. Energy Mater. Sol. Cells. 1992;25(1-2):3-23.

9 Doi T, Tsuda I, Unagida H, Murata A, Sakuta K, Kurokawa K. Experimental study on PV module recycling with organic solvent method. Sol. Energy Mater. Sol. Cells. $2001 ; 67(1-4): 397-403$. 
10 Desideri U, Zepparelli F, Morettini V, Garroni E. Comparative analysis of concentrating solar power and photovoltaic technologies: Technical and environmental evaluations. Appl. Energ. 2013;102: 765-784.

11 Lin CH, Hsu SP, Hsu WC. Silicon Solar Cells: Structural Properties of Ag-Contacts/SiSubstrate. In: Kosyachenko, LA. Solar Cells - Silicon Wafer-Based Technologies. Intech; 2011, p. 93-110.

12 Ratte HT. Bioaccumulation and toxicity of silver compounds: a review. Environmental Toxicology and Chemistry. 1999;18(1):89-108.

13 Grandell L, Lehtil A, Kivinen M, Koljonen T, Kihlman T, Lauri LS. Role of critical metals in the future markets of clean energy technologies. Renew. Energy. 2016;95:53-62.

14 Goe M, Gaustad G. Identifying critical materials for photovoltaics in the US: A multimetric approach. Appl. Energy. 2014;123:387-396.

15 Dias $\mathrm{P}$, Javimczik S, Benevit M, Veit H, Bernardes AM. Recycling WEEE: Extraction and concentration of silver from waste crystalline silicon photovoltaic modules. Waste Management. 2016;57:220-225.

16 Nieland SE, Neuhaus U, Pfaff T, Rädlein E. New approaches for component recycling of crystalline solar modules. In: IEEE, Electronics Goes Green 2012+; 2012; Berlin, Alemanha. IEEE; 2012.

17 Radziemska EK, Ostrowski P. Chemical treatment of crystalline silicon solar cells as a method of recovering pure silicon from photovoltaic modules. Renew. Energy. 2010;35(8):1751-1759.

18 Ketola B, McIntosh KR, Norris A, Tomalia MK. Silicones for Photovoltaic Encapsulation. In: 23rd EUPVSEC; 2008; Valencia, Espanha. EUPVSEC; 2008. p. 2969-2973.

19 Kempe M. Overview of scientific issues involved in selection of polymers for PV applications. In: Conference Record of the 37th IEEE Photovoltaic Specialists Conference; 2011; Seattle, EUA. IEEE: 2011. p. 000085-000090.

20 Dross F, Labat A, Lopez MAP, Raudez R, Bruce A, Kinne S, Komp R. Vacuum-free, cost-effective, developing-country-material-available solar cell encapsulation. Sol. Energy Mater. Sol. Cells. 2006;90(14):2159-2166.

21 ITRPV. International Technology Roadmap for Photovoltaic, 2016 [acesso em 16 maio 2017]. Disponível em: www.itrpv.net/Reports/Downloads/.

22 Jung B, Park J, Seo D, Park N. Sustainable System for Raw-Metal Recovery from Crystalline Silicon Solar Panels: From Noble-Metal Extraction to Lead Removal. ACS Sustainable Chemistry \& Engineering. 2016;4(8):4079-4083.

23 Tammaro M, Rimauro J, Fiandra V, Salluzo A. Thermal treatment of waste photovoltaic module for recovery and recycling: experimental assessment of the presence of metals in the gas emissions and in the ashes. Renewable Energy. 2015;81:103-112.

24 Mancini L, Blengini GA. Analysis of Material Recovery from Silicon Photovoltaic Panels. 2016 [acesso em 15 maio 2017]. Disponível em:

https://www.researchgate.net/publication/301693669_Analysis_of_Material_Recovery_f romSiliconPhotovoltaicPanels.

25 Kang S, Yoo S, Lee J, Boo B, Ryu H. Experimental investigations for recycling of silicon and glass from waste photovoltaic modules. Renew. Energy. 2012;47:152-159.

26 Prado PFA, Tenorio JAS, Espinosa DCR. Alternative Method for Materials Separation from Crystalline Silicon Photovoltaic Modules. In: Energy Technology 2017. Springer; 2017. p. 277-282.

27 Dias P, Benevit MG, Veit HM. Photovoltaic solar panels of crystalline silicon: characterization and separation. Waste Manage. Res. 2016;34(3):235-245. 